\title{
Characteristics of Vanadium and Titanium Microalloyed Steels Forged at Intermediate (Warm) Temperatures through Simulation by Torsion
}

\author{
F. PEÑALBA, M. CARSi, ${ }^{1)}$ C. GARCÍA DE ANDRÉS, ${ }^{1)}$ F. ZAPIRÁIN and M. P. DE ANDRÉS ${ }^{1)}$ \\ INASMET, Co de Portuetxe, 12. Bo de Igara, San Sebastian, Spain. \\ 1) CENIM, Avda. Gregoria del Amo, 8. Madrid, Spain.
}

(Received on June 10. 1991; accepted in final form on October 25, 1991)

\begin{abstract}
This study concerned the response of medium carbon steels microalloyed with vanadium and titanium, to deformation in intermediate ("warm") temperature zone. Titanium varies from 0.003 to $0.039 \%$ in weight.

A critical automotive component (the constant velocity universal joint) warm-forged has been studied by means of a hot torsion simulation technique. Besides its warm-ductility, the influence of the heating temperature before "warm" forging, the "warm" deformation temperature and the weight percentage of $\mathrm{Ti}$ on the final steel properties (grain size, microstructure and hardness), was determined.

It was found that the optimal ductility is reached between 750 and $775^{\circ} \mathrm{C}$ and that the best characteristics (smallest grain size and highest hardness) are obtained with a $\mathrm{Ti}$ weight percentage of $0.019 \%$ and at lower deformation temperatures (from 700 to $750^{\circ} \mathrm{C}$ ). Hence, the automotive component might be warm-forged close to $770^{\circ} \mathrm{C}$ in order to obtain the best mechanical characteristics with enough warm-ductility to avoid warm-forging problems.
\end{abstract}

KEY WORDS: medium carbon steels; vanadium; titanium; "warm" forging; torsion simulation; grain size; hardness; temperature; hot ductility; microstructure.

\section{Introduction}

This paper forms part of an extensive work ${ }^{1-6)}$ made on medium carbon steels, microalloyed with vanadium and titanium (titanium varies from 0.003 to $0.039 \%$ in weight) for the mechanical industry. This extensive work has comprised the study of the $\mathrm{V}$ and $\mathrm{Ti}$ microalloyed steels properties such as continuous cooling diagrams, hot and warm ductility, grain growth, static and dynamic recrystallization, etc., and the influence of both hot and warm forging parameters on the structures and properties of forged critical automotive components. The experiments performed to find the mechanical properties of these steels after both warm and hot forging, were carried out with the aid of torsion techniques. Titanium was selected as the microalloyforming element in the steels, in addition to vanadium, because of its precipitation hardening capacity, with a view to improving the toughness properties. This would be achieved because the vanadium and titaniumvanadium precipitates would control the degree of grain growth and the recrystallized austenitic grain size. ${ }^{7)}$ These precipitates (vanadium and titanium carbonitrides and nitrides) made it possible to reduce the size of the ferritic-pearlitic grain obtained after the transformation during cooling at almost air-cooling rates. The main goal of this extensive work has been to find the smallest percentage of titanium necessary to obtain the best toughness properties, without diminishing other mechanical and metallurgical properties.

The present paper is focused on determining the reaction and suitability of these $\mathrm{V}$ and $\mathrm{Ti}$ microalloyed steels to be forged in the lower area of the austenitic region and in the $\gamma+\alpha$ two-phase region ("intermediate" or "warm" temperatures zone) and the importance of forging parameters in its mechanical characteristics.

Warm forging permits parts for the mechanical (in particular, the automotive) industry to be manufactured with very high mechanical and fatigue properties, simplifying or removing the need of heat treatment. It also gives good dimensional precision (similar to that of "cold" forged products, without the costly preparation of the initial "slug") with a good surface finish (because only a very thin film of oxide is formed at the temperature used for heating) and so allows the partial or total elimination of the machining necessary when deformation takes place at a high temperature. This is an important advantage in economical terms because the machining tends to account for about half the total cost of the part.

One important aspect included in this paper is to investigate the influence of titanium percentage on the ductility at the temperatures used for "warm" forging, the evolution of the ferritic-austenitic structure during 
deformation in the $\gamma+\alpha$ region (intermediate temperatures) and the final properties of the microalloyed steels forged this way.

Finally, a study was conducted on the influence of warm forging temperature on the final microstructures.

\section{Materials and Experimental Techniques}

\subsection{Steels Studied}

Three medium carbon microalloyed steels, with an almost constant $\mathrm{V}$ weight percentage and a variable Ti content were studied. The nitrogen content varied to such a small extent that its influence on the grain size was minimal, although relatively important as regards resistance properties (tensile strength and yield strength). ${ }^{8)}$

The chemical composition in weight percentage and parts per million (p.p.m.) - the gases-is shown in Table 1.

Steels were prepared as follows: Steel 1 was melted using an electric arc melting furnace and a vacuum ladle furnace. It was cast under protective slag into $250 \mathrm{~mm} \times 250 \mathrm{~mm}$ ingots. Later, Steel 1 was hot rolled to $110 \mathrm{~mm}$ square billets. These billets were re-rolled to $38.5 \mathrm{~mm}$ square billets and cooled in air (ensuring that the billets were not stacked). Steels 2 and 3 were melted under protective atmosphere in an induction furnace. These two steels were air cast into $115 \mathrm{~mm} \times 115 \mathrm{~mm}$ ingots. Ingots were then rolled to $38.5 \mathrm{~mm}$ square billets.

Re-heating and finishing last rolling temperatures were close to 1230 and $1080^{\circ} \mathrm{C}$, respectively in all three steels.

\subsection{Warm Experimental Forging}

The forging parameters applied in the torsion simulation are those of an automotive transmission component (constant-velocity universal joint), currently manufactured by warm forging or at intermediate temperatures, because this is generally conducted at temperatures between those of cold forging and those of hot forging.

The joint was forged in 5 operations as shown in Fig. 1. The area studied was the most critical, namely the "crown" (zone 1) of the part (the rest is much easier to form and is not a critical stress area).

The deformation parameters used were obtained by taking the German standard SEP $1123,{ }^{9)}$ the curves typical of the press where the forging was carried out ${ }^{10}$ and the geometry of the successive contours obtained in each operation. All the parameters for the warm forging process which were used in the torsion simulation are listed in Table 2.

Prior to warm forging, the "slugs" were heated in an induction furnace at a rate of $5^{\circ} \mathrm{Cs}^{-1}$.

\subsection{Simulation by Torsion}

Although there are very few papers ${ }^{11)}$ concerning this technique for warm-forging simulation, the technique has been used to simulate hot and warm working processes for several years. ${ }^{12-19)}$ Details of its principles, practice and torsion test sample geometries used may be found in the references. ${ }^{1,12,13,20-23)}$

To find the ductility, the evolution of the austeniticferritic structures during warm forging, the microstructures, grain sizes and final levels of hardness of the

Table 1. Chemical composition in weight percentage and parts per million (p.p.m.).

\begin{tabular}{|c|c|c|c|c|c|c|c|c|c|c|c|c|c|c|c|}
\hline & $\% \mathrm{C}$ & $\% \mathrm{Mn}$ & $\% \mathrm{Si}$ & $r_{c S}$ & $\% \mathrm{P}$ & $\% \mathrm{Cr}$ & $\% \mathrm{Ni}$ & rMo & $\% \mathrm{~V}$ & $\% \mathrm{Ti}$ & $\% \mathrm{Cu}$ & $\% S_{n}$ & $\% \mathrm{Al}$ & \begin{tabular}{l|}
$N_{2}$ \\
$\left(^{*}\right)$
\end{tabular} & $\begin{array}{c}\mathrm{O}_{2} \\
\left(^{*}\right)\end{array}$ \\
\hline $\begin{array}{c}\text { Steel } \\
1\end{array}$ & 0.29 & 1.34 & 0.41 & 0.026 & 0.021 & 0.09 & 0.10 & 0.02 & 0.10 & 0.003 & 0.244 & 0.02 & 0.029 & 167 & 30 \\
\hline $\begin{array}{c}\text { Steel } \\
2 \\
\end{array}$ & 0.29 & 1.28 & 0.34 & 0.028 & 0.017 & 0.13 & 0.08 & 0.01 & 0.09 & 0.019 & 0.134 & 0.015 & 0.036 & 106 & 45 \\
\hline \begin{tabular}{|c|} 
Steel \\
3
\end{tabular} & 0.32 & 1.39 & 0.33 & 0.021 & 0.015 & 0.13 & 0.14 & 0.03 & 0.129 & 0.039 & 0.129 & 0.017 & 0.049 & 148 & 57 \\
\hline
\end{tabular}

(*) p.p.m.

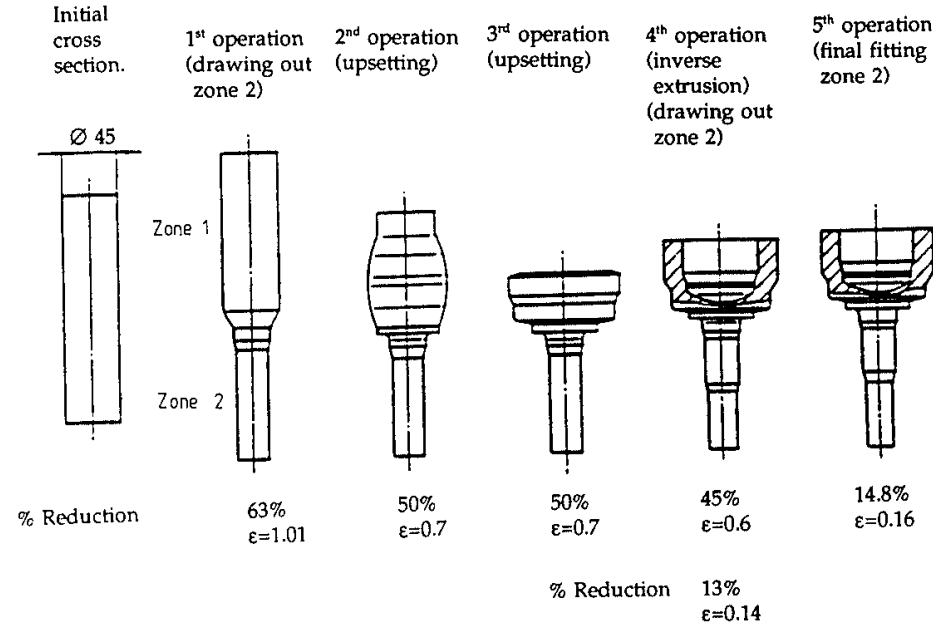

Fig. 1. ("warm") of the constant-velocity universal joint.
Succesive deformation steps in the $\gamma+\alpha$ region 
Table 2. Parameters of warm forging process of the constant-velocity universal joint.

\begin{tabular}{|c|c|c|c|c|c|c|c|c|c|c|c|}
\hline \multicolumn{12}{|c|}{ WARM DEFORMATION IN $\gamma+\alpha$ PHASE } \\
\hline \multirow{2}{*}{$\begin{array}{c}\text { SE } \\
\text { QUE } \\
\text { NCES }\end{array}$} & \multirow{2}{*}{$\begin{array}{l}\text { FURNACE } \\
\text { HEATING } \\
\mathrm{T} \\
\left({ }^{\circ} \mathrm{C}\right)\end{array}$} & \multicolumn{3}{|c|}{$\begin{array}{l}2^{\text {nd }} \text { OPERATION } \\
\left({ }^{*}\right)\end{array}$} & \multicolumn{3}{|c|}{$3^{\text {rd }}$ OPERATION } & \multicolumn{3}{|c|}{$4^{\text {th }}$ OPERATTON } & \multirow{2}{*}{$\begin{array}{l}\text { COOLI } \\
\text { NG } \\
\text { RATE } \\
R_{e} \\
(700- \\
\left.600^{\circ} \mathrm{C}\right) \\
\left({ }^{\circ} \mathrm{Cs}^{-1}\right)\end{array}$} \\
\hline & & $\begin{array}{c}\mathrm{T} \\
\left({ }^{\circ} \mathrm{C}\right)\end{array}$ & $\varepsilon$ & $\underset{\left(s^{\prime \prime}\right)}{\varepsilon}$ & $\begin{array}{c}T \\
\left({ }^{\circ} \mathrm{C}\right)\end{array}$ & $\varepsilon$ & 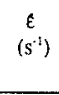 & $\begin{array}{c}\mathrm{T} \\
\left({ }^{\circ} \mathrm{C}\right)\end{array}$ & $\varepsilon$ & $\underset{\left(s^{\prime}\right)}{\varepsilon}$ & \\
\hline I & 700 & 700 & 0.69 & 7.3 & 700 & 0.69 & 13.4 & 700 & 0.59 & 9.9 & 4.2 \\
\hline II & 725 & 725 & 0.69 & 7.3 & 725 & 0.69 & 13.4 & 725 & 0.59 & 9.9 & 3.90 \\
\hline III & 750 & 750 & 0.69 & 7.3 & 750 & 0.69 & 13.4 & 750 & 0.59 & 9.9 & 3.65 \\
\hline IV & 775 & 775 & 0.69 & 7.3 & 775 & 0.69 & 13.4 & 775 & 0.59 & 9.9 & 3.40 \\
\hline $\mathrm{v}$ & 825 & 782 & 0.69 & 7.3 & 825 & 0.69 & 13.4 & 825 & 0.59 & 9.9 & 3.10 \\
\hline
\end{tabular}

(*) There were fractures during deformation at $650^{\circ} \mathrm{C}$.

Table 3. Parameters for simulation by torsion of the deformation in $\gamma+\alpha$ phase ("warm").

\begin{tabular}{|c|c|c|c|c|c|c|c|}
\hline OPERATIONS & $\begin{array}{c}\text { TIME } \\
\text { Deformation } \\
(s)\end{array}$ & $\begin{array}{c}\text { HEIGHT } \\
\text { Zone } 1 \\
(\text { (otal })(\mathrm{mm})\end{array}$ & \multicolumn{2}{|c|}{$\begin{array}{l}\text { STRAIN } \\
\% \quad \begin{array}{c}k=\ln \left(h_{1} / h_{1}\right) \\
(I)\end{array}\end{array}$} & $\begin{array}{l}\text { WAITING } \\
\text { TIME } \\
(\mathrm{s})\left({ }^{*}\right)\end{array}$ & $\begin{array}{c}\text { E (STRAIN } \\
\text { RATE) }\left(\mathrm{s}^{-1}\right) \\
\left({ }^{* *}\right)\end{array}$ & $\begin{array}{c}\text { FORGING } \\
\text { TEMPER. } \\
\left({ }^{\circ} \mathrm{C}\right)\end{array}$ \\
\hline $\begin{array}{l}\text { Total Length } \\
\text { InitialCross Section }\end{array}$ & & $(108+41)$ & & & & & \\
\hline $\begin{array}{l}\text { 1st Operation } \\
\text { (drawing out) }\end{array}$ & $(0.66)$ & 108 & $(6.3)$ & $\begin{array}{c}1.01 \\
\text { (aone 2) }\end{array}$ & & & $(775)$ \\
\hline Pause & & & & & $(1.05)$ & & \\
\hline $\begin{array}{l}\text { 2nd Operation } \\
\text { (upsetting) }\end{array}$ & 0.66 & 54 & 50 & $\begin{array}{c}0.69 \\
\text { (zone 1) }\end{array}$ & & $7.3(\#)$ & 775 \\
\hline Pause & & & & & (1.05) & & \\
\hline $\begin{array}{l}\text { 3rd Operation } \\
\text { (upsetting) }\end{array}$ & 0.66 & 25 & 50 & $\begin{array}{c}0.69 \\
\text { (zone 1) }\end{array}$ & & $13.4(\#)$ & 775 \\
\hline Pause & & & & & $(1.05)$ & & \\
\hline $\begin{array}{c}\text { 4th Operation } \\
\text { (inverse extrusion) }\end{array}$ & 0.66 & 45 & 45 & $\begin{array}{c}0.59 \\
\text { (zone } 1)\end{array}$ & & 9.9 (\#\#) & $775 / 825$ \\
\hline Pasusc & & & & & $(1.05)$ & & \\
\hline $\begin{array}{l}\text { 5th Operation (final } \\
\text { coining) }\end{array}$ & $(0.66)$ & 45 & $(14.8)$ & $\begin{array}{c}0.15 \\
\text { (zone 2) }\end{array}$ & & & $(775 / 825)$ \\
\hline
\end{tabular}

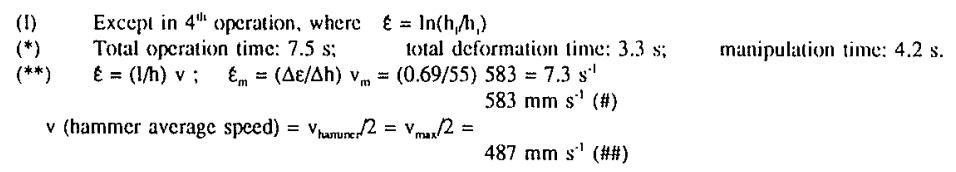

three microalloyed steels under study, torsion sample pieces were tested as follows:

\subsubsection{Ductility at Intermediate Temperatures}

The ductility gives the range of temperatures at which warm forging is performed most efficiently and with the least deterioration in the equipment.

Warm torsion tests were conducted until rupture (maximum deformation) at deformation rates of $\dot{\varepsilon}=$ $14 \mathrm{~s}^{-1}$ between 650 and $1000^{\circ} \mathrm{C}$, at $50^{\circ} \mathrm{C}$ intervals and the ductility curves of the three steels were obtained. The ductility curves for the same range of temperatures at three other different deformation rates $\dot{\varepsilon}=1 \mathrm{~s}^{-1}$, $\dot{\varepsilon}=7 \mathrm{~s}^{-1}$ and $\dot{\varepsilon}=21 \mathrm{~s}^{-1}$ were obtained in Steel 1 .

\subsubsection{Torsion Simulation of Forging at Intermediate Temperatures}

With the experimental results listed in Table 2, five deformation runs were performed with increasing temperatures (from 650 to $825^{\circ} \mathrm{C}$ ) and with the deformation values $(\varepsilon)$ and deformation rates $(\dot{\varepsilon})$ listed in Table 3 . As may be seen from Table $2,1^{\text {st }}$ and $5^{\text {th }}$ operations of the deformation process did not affect the "crown" (zone 1) area, so these were not taken into account in the simulation.

The best runs (temperatures) were selected by studying the final properties of each test piece.

Apart from the test pieces obtained with close to air cooling rates $\left(R_{c}=3.10-4.20^{\circ} \mathrm{C} \mathrm{s}^{-1}\right)$ between 700 and $600^{\circ} \mathrm{C}$, some test pieces were frozen (by quenching) in the intermediate steps to study the influence of the successive deformations on the final grain size.

Torsion tests were also conducted in $\gamma+\alpha$ region with furnace heating temperatures of 1050 and $950^{\circ} \mathrm{C}$ and deformation runs at 825,775 and $750^{\circ} \mathrm{C}$ to find the influence of the heating temperature on the final properties $\left(1050^{\circ} \mathrm{C}\right.$ heating temperature is higher than the complete dissolution temperature of the vanadium carbonitrides and nitrides ${ }^{24}$ ). 


\section{Experimental Results}

The warm ductility curves in $y+\alpha$ region of the three steels with deformation rates of $\dot{\varepsilon}=14 \mathrm{~s}^{-1}$ (maximum deformation rate in real forging) and a temperature between 650 and $1000^{\circ} \mathrm{C}$ (rather broader than the warm field between 650 and $850^{\circ} \mathrm{C}$ ), showed Steel 1 to be the most ductile (Fig. 2). Steels 2 and 3 had less and almost similar ductility. Relative maximum ductility was reached at temperature between 775 and $825^{\circ} \mathrm{C}$.

At temperatures between 650 and $775^{\circ} \mathrm{C}$, the ductility (maximum deformation) of Steel 1 at medium and high deformation rates $(\dot{\varepsilon})$ increased rapidly and reached a maximum at around $775^{\circ} \mathrm{C}$ (Fig. 3). In this temperature range, the ductility of Steel 1 rose in line with the deformation rate $(\dot{\varepsilon})$. At low $\dot{\varepsilon}$ (less than $7 \mathrm{~s}^{-1}$ ), the ductility varied less with temperature and the maximum observed at higher rates did not appear between 775 and $825^{\circ} \mathrm{C}$. At high $\dot{\varepsilon}$, there was a rise in the ductility between 750 and $775^{\circ} \mathrm{C}$. This diminished notably in the range from 775 to $850^{\circ} \mathrm{C}$. The ductility then increased again as the temperature rose from $850^{\circ} \mathrm{C}$.

Table 4 lists the parameters obtained in each steel by torsion simulation of the warm forging deformation: austenitic grain sizes, final microhardness values, final ferritic-pearlitic grain sizes, the volume fractions of the ferritic and pearlitic phases and the hardness values obtained after the sudden cooling (quenching) which followed the last deformation (obtaining a high-strength, two-phase martensite-ferrite steel).

The final microhardness values increased as the deformation temperatures lowered and the increase was significantly larger at values below $775^{\circ} \mathrm{C}$. The lowest levels of hardness correspond to Steels 1 and 2, which had a smaller amount of titanium, while Steel 3 had the highest level because it contained bainite.

It was noted that the austenitic grain size decreased with the deformation temperature and that Steel $2 \mathrm{had}$ the smallest grain. The ferritic or pearlitic grain sizes were very similar and diminished with the deformation temperature, notably more so at temperatures below $775^{\circ} \mathrm{C}$. Steel 2 also had the smallest grain sizes. The volume fraction of the ferritic (pearlitic) phase of the three steels diminished (increased) slightly as warm forging was performed at higher temperatures. The pearlite volume fraction was seen to increase from Steel 1 to Steel 2. Steel 3 could not be compared because it contained bainite.

Figures 4 to 7 show the final ferritic-pearlitic structures obtained in the three steels after the $\gamma+\alpha \rightarrow \alpha+p$ (pearlite) transformation, at a cooling rate of $R_{\mathrm{c}}=4.2-3.1^{\circ} \mathrm{Cs}^{-1}$ (between 700 and $600^{\circ} \mathrm{C}$ ) at each deformation tempera-
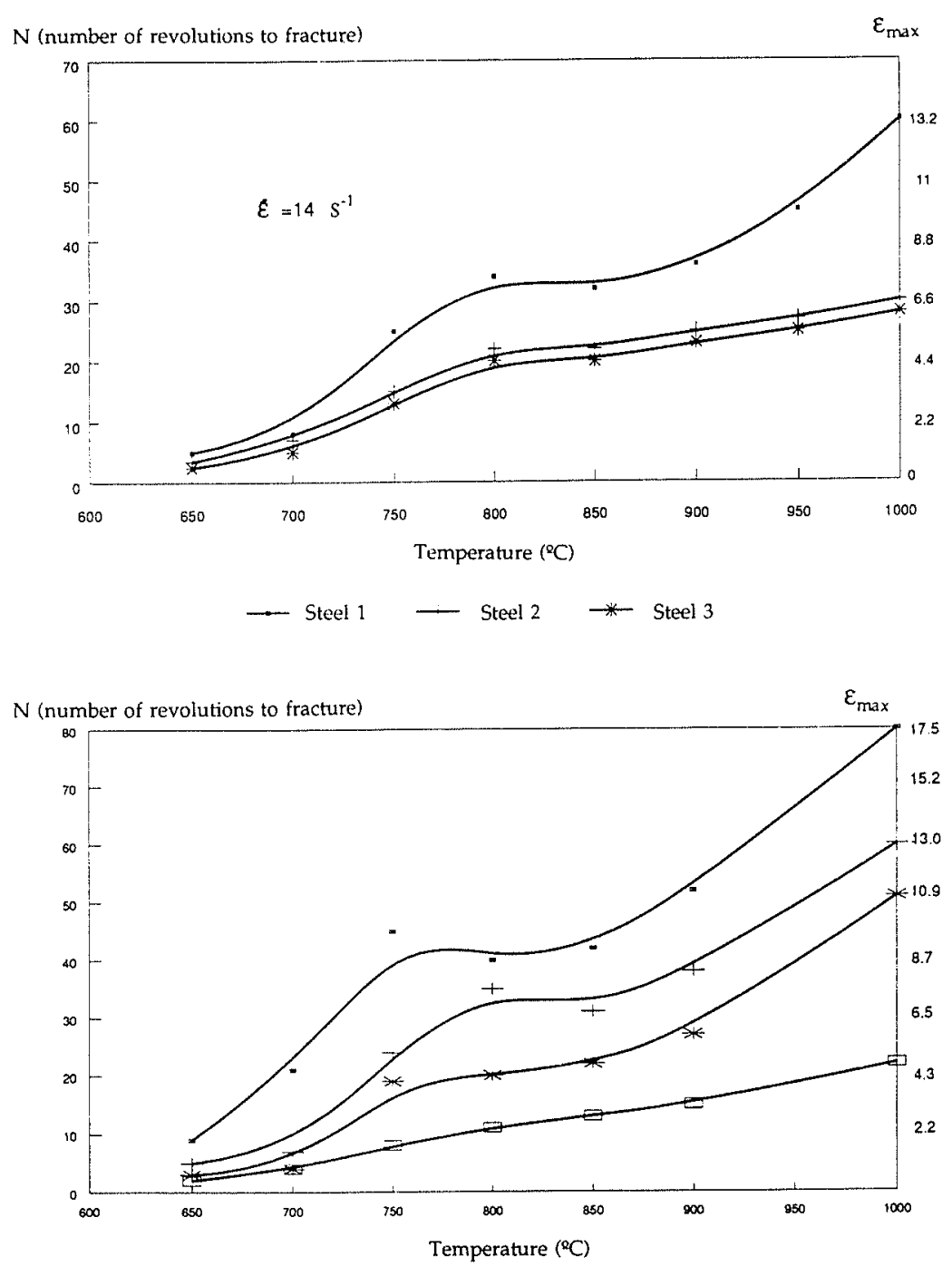

Fig. 2.

Ductility curves of the three stecls in the $y+x$ region.

Fig. 3.

Variation of the ductility in the $\gamma+\alpha$ region with the deformation rate (Steel 1) 
Table 4. Relation of the $\gamma+\alpha$ region deformation sequences with the parameters: asutenitic grain size, ferritic-pearlitic grain size, quenched samples hardness (ferritic-martensitic), ferritic-pearlitic hardness, ferrite volume fraction and pearlite volume fraction.

\begin{tabular}{|c|c|c|c|c|c|c|c|c|c|c|c|c|c|c|c|c|}
\hline & & \multicolumn{15}{|c|}{$\begin{array}{l}\text { TEMPERATURE SEQUENCES OF DEFORMATION IN } \gamma+\alpha \\
\tau_{y}, \alpha\left({ }^{\circ} \mathrm{C}\right)\end{array}$} \\
\hline & & \multicolumn{3}{|c|}{1} & \multicolumn{3}{|c|}{2} & \multicolumn{3}{|c|}{3} & \multicolumn{3}{|c|}{4} & \multicolumn{3}{|c|}{5} \\
\hline & & 700 & 700 & 700 & 725 & 725 & 725 & 750 & 750 & 750 & 775 & 775 & $775 * *$ & 825 & 825 & $825 * *$ \\
\hline \multirow{3}{*}{$\begin{array}{l}\mathrm{d} \\
(\mu \mathrm{m})\end{array}$} & Steel 1 & & & & 6.1 & 5.5 & 5.5 & & & & & & & 14 & 13 & 13 \\
\hline & Steel 2 & & & & 5.5 & 5.3 & 5.4 & & & & & & & 7.5 & 7.0 & 7.0 \\
\hline & Steel 3 & & & & 5.9 & 5.8 & 5.7 & & & & & & & 12 & 10 & 10 \\
\hline \multirow{3}{*}{$\begin{array}{l}\mathrm{d}_{\mathrm{w}} / \mathrm{d} \mathrm{d}_{\mathrm{r}} \\
(\mu \mathrm{m})\end{array}$} & Steel 1 & & & & & & $2.9 / 2.9$ & & & $4.1 / 4.4$ & & & $5.7 / 5.9$ & & & $6.4 / 6.7$ \\
\hline & Steel 2 & & & $1.5 / 1.5$ & & & $2.8 / 2.8$ & & & $3.9 / 4.0$ & & & $5.6 / 5.7$ & & & $6.2 / 6.4$ \\
\hline & Steel 3 & & & $2.1 / 2.1$ & & & $2.9 / 2.9$ & & & $3.8 / 4.0$ & & & $5.7 / 5.9$ & & & $6.4 / 6.6$ \\
\hline \multirow{3}{*}{$\begin{array}{l}\mathrm{H}_{\mathrm{u}, \mathrm{M}} \\
(\mathrm{HV} \text { 10) }\end{array}$} & Steel 1 & 493 & 560 & & 566 & 560 & 592 & & & & 606 & 570 & 592 & 585 & 560 & 542 \\
\hline & Steel 2 & & & & & & & & & & & & & & & \\
\hline & Stcel 3 & & & & & & & & & & & & & & & \\
\hline \multirow{3}{*}{$\begin{array}{c}H_{u \cdot p} \\
(H V 10)\end{array}$} & Stecl 1 & & & & & & 261 & & & 247 & & & 235 & & & 228 \\
\hline & Steel 2 & & & 264 & & & 255 & & & 238 & & & 226 & & & 213 \\
\hline & Steel 3 & & & & & & 271 & & & 254 & & & 245 & & & 234 \\
\hline \multirow{3}{*}{$v_{u}$} & Sleell & & & & & & 0.76 & & & 0.74 & & & 0.72 & & & 0.69 \\
\hline & Steel 2 & & & 0.71 & & & 0.69 & & & 0.66 & & & 0.64 & & & 0.62 \\
\hline & Steel $3 *$ & & & & & & 0.45 & & & 0.43 & & & 0.41 & & & 0.39 \\
\hline \multirow{3}{*}{$v_{p}$} & sicw) & & & & & & 0.24 & & & 0.26 & & & 0.28 & & & 0.31 \\
\hline & Steel 2 & & & 0.29 & & & 0.31 & & & 0.34 & & & 0.36 & & & 0.38 \\
\hline & Steel 3* & & & & & & 0.25 & & & 0.26 & & & 0.32 & & & 0.37 \\
\hline
\end{tabular}

(*) The difference to $I$ is the bainite volume fraction

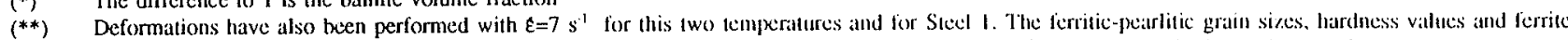
and pearlite volume fractions obtained in this case were similar to those achieved with the real deformation rates indicated in table 3.

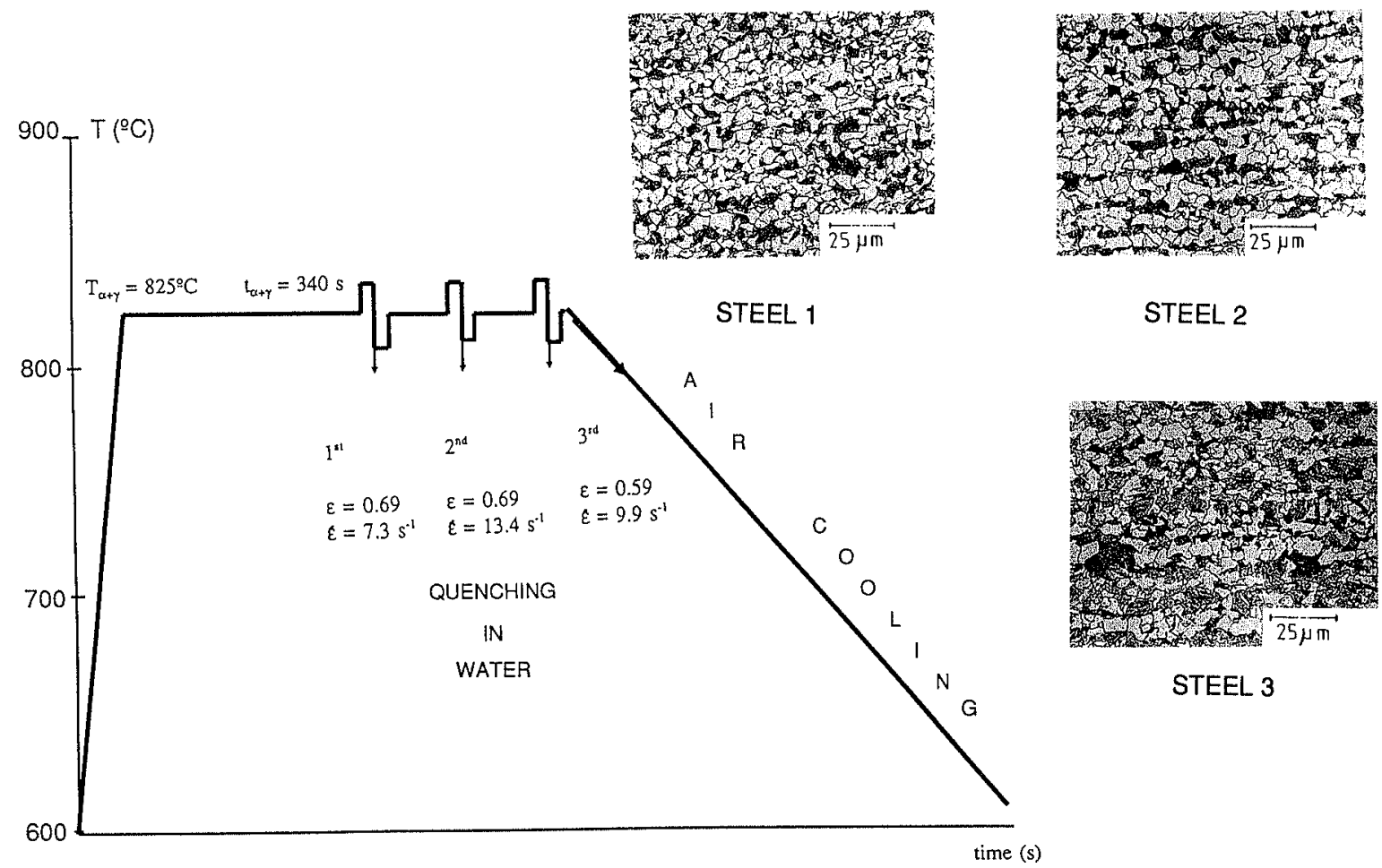

Fig. 4. Deformation sequence at $825^{\circ} \mathrm{C}$ and final structures obtained in the three studied steels

ture between 725 and $825^{\circ} \mathrm{C}$.

Torsion sample pieces deformed at warm temperatures after heated at 950 and $1050^{\circ} \mathrm{C}$, were tested for Steel 1 , in order to determine whether the hardness of the steels could be raised above that obtained with warm forging in accordance with Table 3. At 950 and $1050^{\circ} \mathrm{C}$ a 


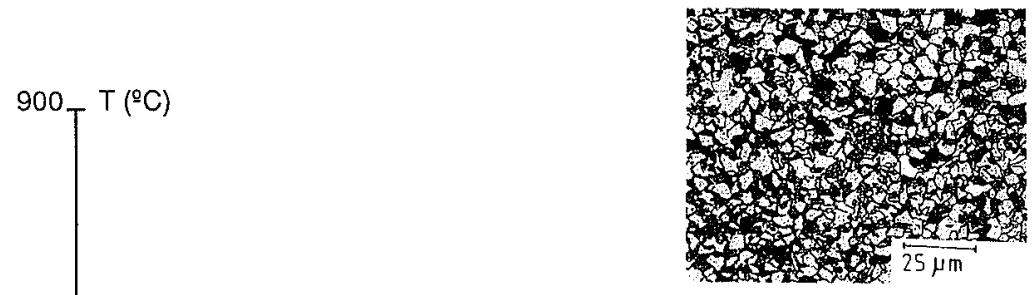

STEEL 1

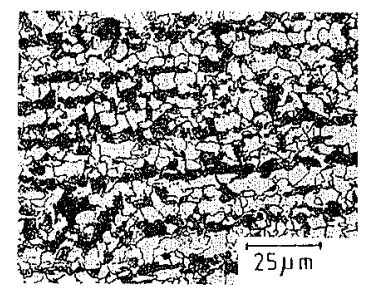

STEEL 2
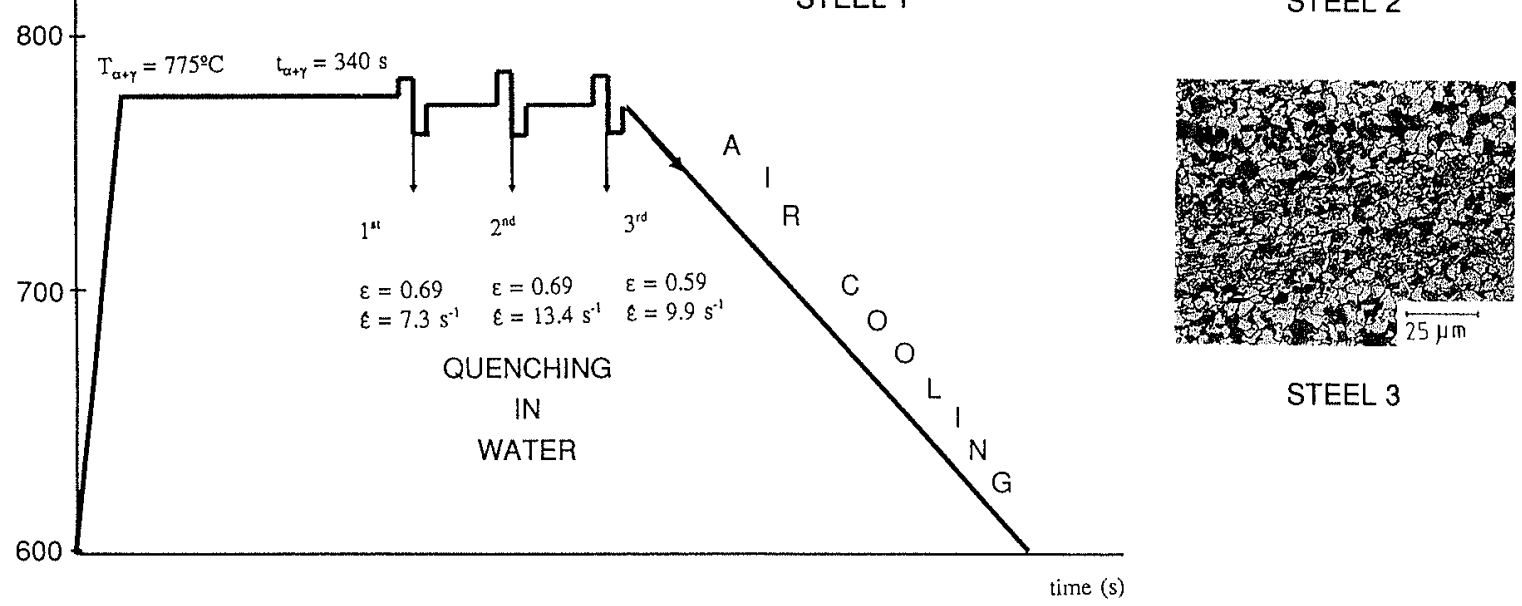

STEEL 3

Fig. 5. Deformation sequence at $775^{\circ} \mathrm{C}$ and final structures obtained in the three studied steels.

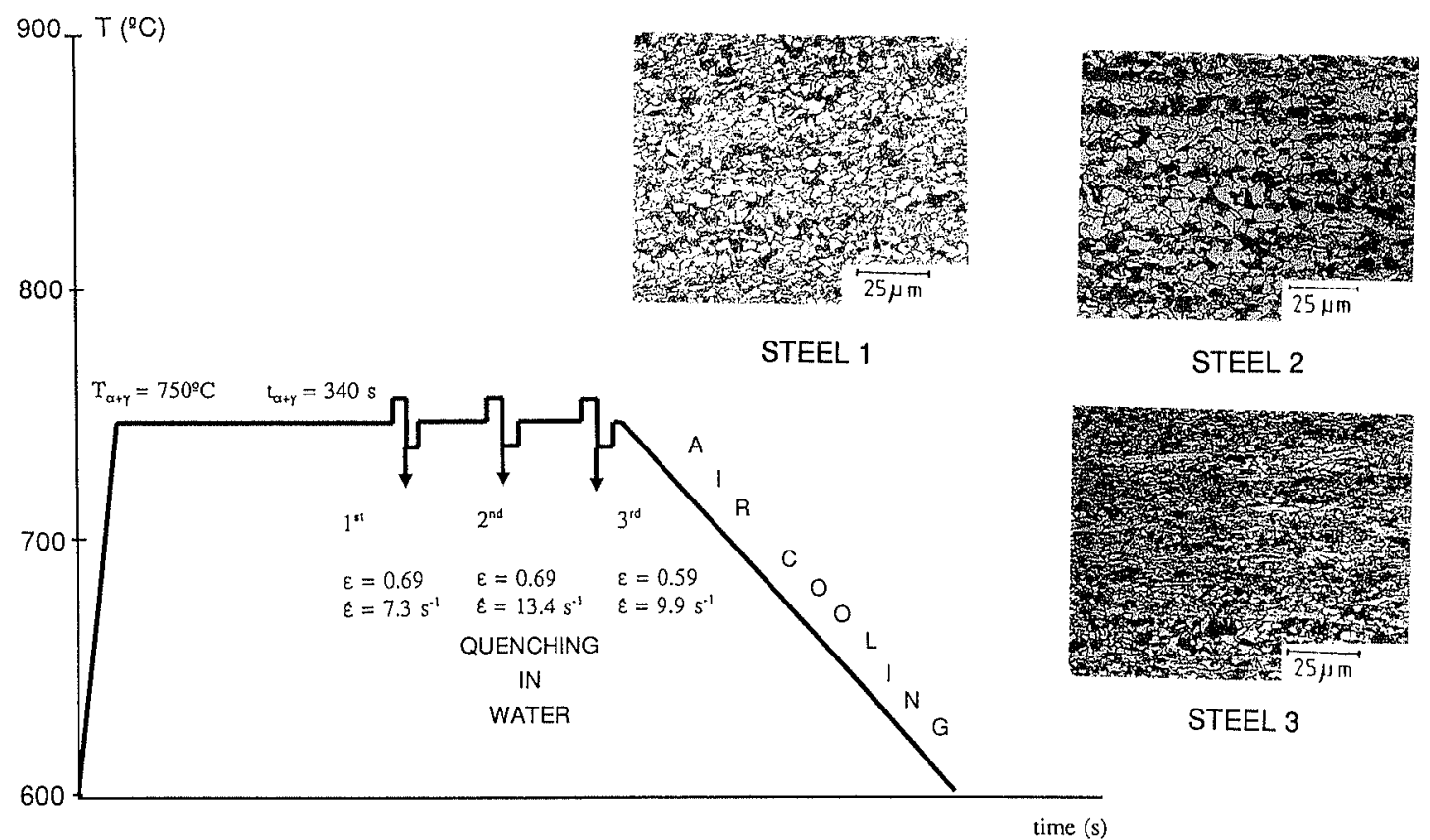

Fig. 6. Deformation sequence at $750^{\circ} \mathrm{C}$ and final structures obtained in the three studied steels.

larger amount of titanium compounds dissolve, so in a subsequent cooling process they could help to increase the hardening by precipitation. The temperatures selected corresponded to a higher than $80 \%$ and total solubility of the vanadium respectively. ${ }^{24)}$ But they implicated two growing levels of energy consumption (necessary for the heating) and of the surface deterioration.

Table 5 displays the parameters measured at these heating temperatures: microhardness, pearlitic-ferritic grain size and the volume fractions of the phases. To facilitate a comparison, Table 5 also includes the parameters shown in Table 3.

The microhardness only increased significantly at the highest heating temperature. It increased very slightly in line with deformation at lower temperatures. In contrast, the grain sizes (mainly the pearlitic grain) varied significantly in line with the heating and deformation temperatures. This increase was lower in Steel 2 than in the other two. Lastly, the volume fractions of the final ferritic and pearlitic phases were almost identical.

\section{Discussion of the Results}

Lower ductility in this two-phase area of Steels 2 and 3 (Fig. 2) was due to the manufacturing process, because 


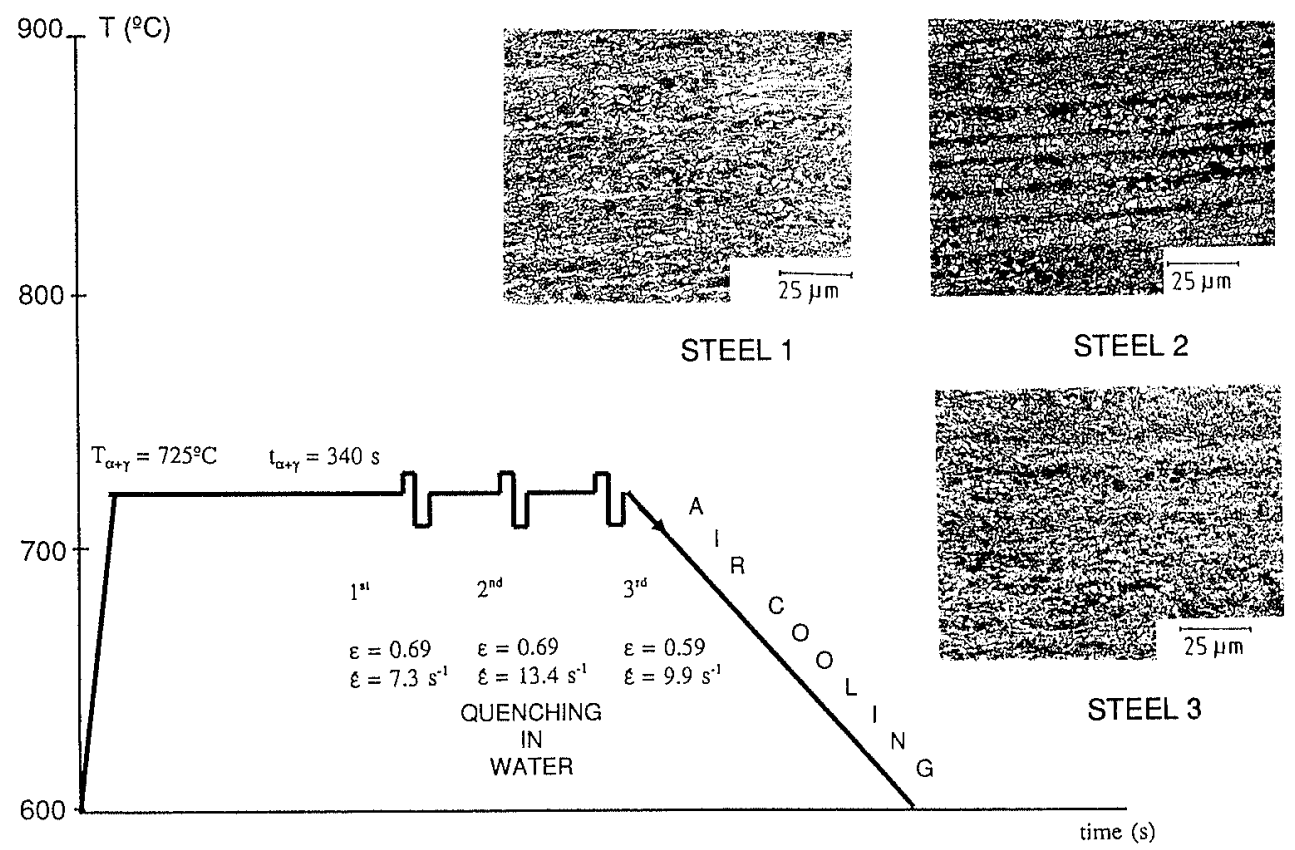

Fig. 7. Deformation sequence at $725^{\circ} \mathrm{C}$ and final structures obtained in the three studied steels.

Table 5. Relation of the heating temperatures (austenitizing or quasiaustenitizing) with the different parameters: final hardness $\left(H V_{\alpha+p}\right)$, ferritic $\left(d_{p}\right)$ grain sizes and ferritic $\left(V_{\alpha}\right)$ and pearlitic $\left(V_{p}\right)$ volume fractions, for Steel 1.

\begin{tabular}{|c|c|c|c|c|c|c|c|c|c|c|}
\hline & $\begin{array}{l}\text { HEATING } \mathrm{T} \text {. } \\
\mathrm{T}_{r} \mathrm{~T}_{r+\alpha}\left({ }^{\circ} \mathrm{C}\right)\end{array}$ & 750 & 950 & 1050 & 775 & 950 & 1050 & 825 & 950 & 1050 \\
\hline & $\begin{array}{c}\text { DEFORMATION T. } \\
\mathrm{T}_{\gamma+\alpha}\left({ }^{\circ} \mathrm{C}\right)\end{array}$ & 750 & 750 & 750 & 775 & 775 & 775 & 825 & 825 & 825 \\
\hline \multirow{5}{*}{$\begin{array}{l}\mathrm{P} \\
\mathrm{A} \\
\mathrm{R} \\
\mathrm{A} \\
\mathrm{M} \\
\mathrm{E} \\
\mathrm{T} \\
\mathrm{E} \\
\mathrm{R} \\
\mathrm{S}\end{array}$} & $\begin{array}{l}\mathrm{HV}_{\alpha+p} \\
\text { (HV10) }\end{array}$ & 247 & 246 & 255 & 235 & 235 & 248 & 228 & 229 & 244 \\
\hline & $\begin{array}{c}\mathrm{d}_{\alpha} \\
(\mu \mathrm{m})\end{array}$ & 3.0 & 3.1 & 3.1 & 3.2 & 3.3 & 4.1 & 3.5 & 3.8 & 5.3 \\
\hline & $\begin{array}{c}d_{p} \\
(\mu m)\end{array}$ & 3.2 & 3.4 & 4.9 & 3.7 & 3.9 & 5.3 & 3.9 & 4.9 & 6.2 \\
\hline & $v_{\alpha}$ & 0.74 & 0.75 & 0.74 & 0.72 & 0.74 & 0.71 & 0.69 & 0.72 & 0.70 \\
\hline & $V_{p}$ & 0.26 & 0.25 & 0.26 & 0.28 & 0.26 & 0.29 & 0.31 & 0.28 & 0.30 \\
\hline
\end{tabular}

they were air cast, while Steel 1 was vacuum melted and was cast under protective slag, so the content of non-metallic inclusion rose drastically. The increased ductility of Steel 1 (Fig. 3) in the 750 to $775 / 800^{\circ} \mathrm{C}$ range (which in turn increased in line with the deformation rate) was similar to that observed by Pierson et al. ${ }^{11}$ It was caused by the evolution of the phases forming the $\gamma+\alpha$ two-phase structure, which lead to a transitory plasticity and resulted in the significant increase in the ductility of the material.

The fact that the hardness increased in line with the decrease of the warm deformation temperature (Fig. 8) is related to the increased brittleness caused by the rise in the amount of deformed proeutectoid ferrite. The largest rise of this parameter occurred in Steel 3 $(\mathrm{Ti}=0.039 \%)$ was a result of the presence of a harder phase, bainite, in its structure.

Steel 2 with $0.019 \%$ of titanium had the smallest austenitic grain size at the same deformation tempera- ture simply because of the favourable effect caused by the fine TiN or $\mathrm{Ti}(\mathrm{C}, \mathrm{N})$ type precipitates, (mainly observed in this steel $\left.{ }^{11}\right)$, on the degree of austenitic grain growth. ${ }^{24)}$ The difference between the austenitic grain size of Steel 2, and that of the other two steels increased as the warm forging was performed at higher temperatures.

The ferritic and pearlitic grain sizes were almost identical for each deformation temperature. These grain sizes were also very similar in each of the three steels. This is an indication of the relative minimum influence of the titanium content on the ferritic and pearlitic grain size during warm forging (Fig. 8). However, both the ferritic grain and the pearlitic grain (Table 5) did grow in size as the heating and deformation temperatures rose. This shows how important these two temperatures are on the toughness characteristics. The volume fraction of ferrite (or pearlite) diminished (rose) with forging at higher temperatures (Table 4 ) because a 


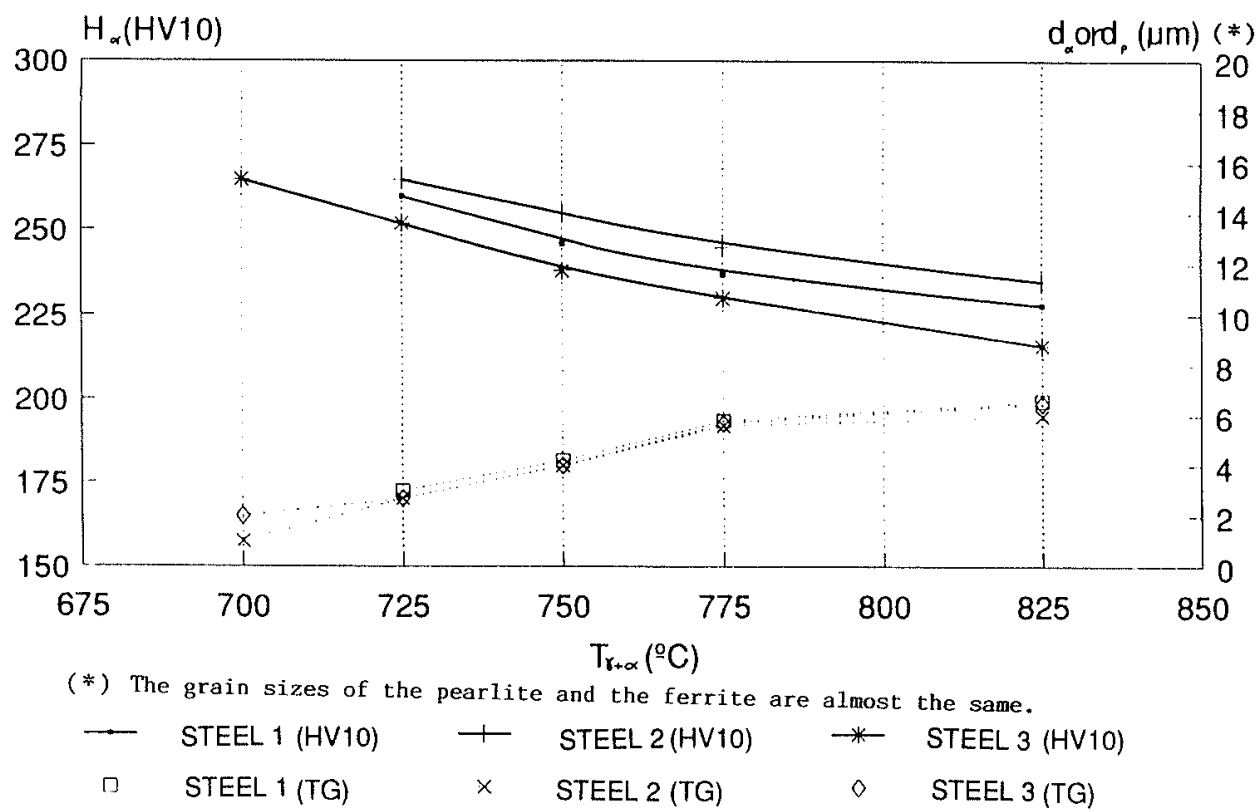

Fig. 8. Variation of the grain sizes and the microhardness with the final temperatures of deformation performed in the $\gamma+x$ region.

larger amount of ferrite was transformed into austenite and, consequently, part of this austenite was transformed into pearlite, so reducing the amount of ferrite. The reason that Steel 1 has a larger ferrite volume fraction than Steel 2 is due to fact that Steel 1 has less hardenability.,4)

\section{Conclusions}

(1) Warm forging gives these vanadium and titanium microalloyed steels a level of hardness which increases strongly in line with a decrease of the deformation temperature. This means that the strength of the automotive component studied (a constant-velocity universal joint) can be controlled only varying the process temperature (as long as the facility permits deformation at all the temperatures tested here).

(2) In these $\mathrm{V}$ and $\mathrm{Ti}$ microalloyed steels the austenitic grain size and the final pearlitic and ferritic grain sizes also diminish in line with the drop in the final warm forging temperature. The smallest grain sizes correspond to levels of titanium of $0.019 \%$ (or better for quantities of titanium of 0.010 to $0.020 \%$ ). The final pearlitic and ferritic grain sizes are almost identical at each temperature, very small and similar in the three steels (or levels of titanium) studied. The main differences have been found in the pearlitic grain size at heating temperatures prior to deformation of above $950^{\circ} \mathrm{C}$, because only the pearlitic grain (not the ferritic grain) increases in line with this temperature. The pearlite volume fraction obtained after warm forging grows as the deformation temperature rises.

(3) The toughness values given by forging at intermediate temperatures must be very high because of the very small ferritic and pearlitic grain sizes obtained. However, these toughness values will be very similar in all the warm-forging temperatures between 700 and $775^{\circ} \mathrm{C}$, because the increase in toughness produced by the decrease in ferritic and pearlitic grain sizes (as the warm-deformation temperature) is balanced by the decrease in toughness produced by the increase in strength (hardness). This would lead to highly reliable automotive components, with excellent properties, excellent good dimensional precision and a surface quality which, in many cases, would eliminate the need for the forged component to be machined afterwards. By eliminating the machining, the cost of the part would drop considerably (by approximately $50 \%$ of the total cost of the finished component). Further savings would be made in energy costs by reducing the temperature of heating prior to warm forging compared to the temperature of heating prior to hot forging.

(4) The strength could be improved by raising the temperature of heating prior to forging $\left(\geq 1050^{\circ} \mathrm{C}\right)$, although the surface quality could be affected by the appearance of a thicker film of oxidation.

(5) The ductility in the warm forging range of temperatures (normally between 700 and $825^{\circ} \mathrm{C}$ ) of these $\mathrm{V}$ and $\mathrm{Ti}$ microalloyed steels drops in line with the forging temperature, except between 750 and $775^{\circ} \mathrm{C}$. In this range, the ductility increases making it the most appropriate for this type of forging. The higher the rate of deformation during the forging process, the bigger the increase.

(6) The automotive component (a constant-velocity universal joint) might be warm-forged close to $770^{\circ} \mathrm{C}$ in order to obtain the best mechanical characteristics with enough warm-ductility to avoid warm-forging problems.

\section{Acknowledgement}

The authors acknowledge with gratitude the financial support received from the Industry and Trade Department of the Government of the Basque Autonomous Community. 


\section{REFERENCES}

1) F. Penãlba: Desitation, Complutense University of Madrid, Physics Faculty, (1991).

2) C. García, M. Carsí, F. Peñalba and M. P. de Andrés: J. Mater. Sci., (Accepted to be published).

3) F. Peñalba, M. Carsí, C. García de Andrés and F. Zapirain: Mém. Et. Sci. Rev. Mét., 2, (1991), 77.

4) F, Peñalba, C. García de Andrés, M. Carsí and F. Zapirain: Nat. Conf. on Metallurgical Science and Technology, Vol. III, Madrid, (1991), 97.

5) F. Peñalba, M. Carsí, C. Garcia de Andrés and F. Zapirain: IV Nat. Conf. on Heat Treatments, Zaragoza, (1990), 291.

6) F. Peñalba, M. Carsi, C. Garcia, M. P. De Andrés and F. Zapirain: Int. Conf. on Grain Growth in Polycrystalline Materials, Rome, (1991), 35.

7) M. Korchynsky: Processing, Microstructure and Properties of HSLA Steels, ed. by A. J. De Ardo, Pennsylvania, (1988), 169.

8) H. Osazu et al.: SAE Technical paper Series 860131, Int. So. of Automotive Eng., Detroid, (1986), 1.

9) German Standard SEP 1123, Verlag Stahleisen, RFA, (1986), 1.
10) Technical data Schuler PM 1250-5, Germany, (1981), 1.

11) G. Pierson et al:: Mém. El Sci. Rev. Mét., Mai, (1984), 239.

12) Y. Desalos and A. Le Bon: Rev. Trait. Therm., 145 (1980), 59.

13) J. J. Urcola and M. Fuentes: Deformación Metálica, 66 (1981), 48.

14) ECSC-Steel Research Contract P-2630, ed. by Commission of the European Communities, Brussel, (1990), I

15) G. Robiller et al:: Stahl u. Eisen, 4 (1987), 159

16) W. Knuds et al:: Sheffield Int. Conf. on Hot working and forming Process, Vol. 1, (1979), 9.1.

17) C. Rossard: Chem. Ing. Tech., 6 (1961), 1533.

18) Steel Research Reports EUR 5828, ed. by Commission of the European Communities, Luxembourg, (1977), (37).

19) Steel Research Reports EUR 6131, ed. by Commission of the European Communities, Luxembourg, (1978), 162.

20) A. Faessel: Commission des laminoirs, C.I.T. 4, (1976), 875.

21) J. Coupry: Revue de L'Aluminium, Mai (1976), 259.

22) G. R. Casanova et al.: Formability of Metallic Materials-2000 AD, ASTM, STP 753, (1983), 189

23) E. Rauch et al.: Act. Metall, 33 (1985), 465.

24) S. S. Hansen: Met. Soc. of AIME, (1987), 155. 